\title{
Sustainable Development: Economic, Social, and Environmental Sustainability in Asian Economies
}

Fizza Younis and Muhammad Aslam Chaudhary ${ }^{1}$

\begin{abstract}
The major aim of this study is to analyze relationship between social, economic, and environmental sustainability. Panel analysis is carried out for nineteen Asian economies, which are divided into three sub-groups; South Asia, Southeast Asia, and Central \& East Asia. To draw empirical evidences meta-system has been utilized. Results divulge a trade-off between economic and environmental sustainability when all countries are considered. Whilst, in the case of sub-regions no such trade-off is apparent. Furthermore, interactions between economic, social, and environmental sustainability is statistically significant. It implies that these factors are interdependent and affect each other. Thus, the allocation of scarce financial resources should seek convergence between economic, social, and environmental sustainability dimensions of sustainable development. The empirical evidences also indicated that Globalization has a negative impact on environmental sustainability in South Asia, while its impact was positive in Southeast and Central \& East Asian regions. Social inclusiveness has a positive relationship with social sustainability, while, technological change has a positive impact on economic sustainability, in all regions of Asia. Thus, these factors may act as transmission channels to achieve sustainable development in the region and should be the focus of economic policies.
\end{abstract}

Keywords: Sustainable Development, Economic Sustainability, Social Sustainability, Environmental Sustainability, Empirical Analysis, South East Asia, Development Economics, Regional Comparison

JEL Classification: O1, O10, O13, O15, O2, Q01, C3, C50

\section{Introduction}

The economic development has been a focal point of economic policies from a long time, but it has been only for the last few decades that sustainable development (SD) came to the forefront of economic debate and it gained significant importance. During the last few years, environmental protection and

\footnotetext{
${ }^{1}$ The authors are PhD Scholar and Professor \& Head of Economics Department at The University of Lahore, Lahore, respectively. The paper is based upon first author's Ph.D. research work. Corresponding Author's Email: aslamchm@ hotmail.com
} 
social integration have found their way into mainstream economics. It has become increasingly clear that without social equity and environment sustainability, economic growth cannot be sustained (Kates, Parris, \& Leiserowitz, 2005). Sustainable development has now become the subsequent goal of all economic activities, as the former Secretary-General of the United Nations once said: "Sustainable development is the pathway to the future we want for all. It offers a framework to generate economic growth, achieve social justice, exercise environmental stewardship and strengthen governance." -Ban Ki-moon (2013)

Sustainable development encompasses economic sustainability ${ }^{2}$, social sustainability $^{3}$, and environmental sustainability ${ }^{4}$. Often conflicts arise between social, economic, and/or sustainable environmental objectives; especially due to resource constraints. However, to achieve economic security for the sake of future generations, it is paramount to sustain development. Extended neoclassical growth models show that government policies, accumulation of human capital, and technology diffusion are very important for economic sustainability (Barro, 1996; Michie, 2001). Moreover, institutional quality and sustainable economic growth are irrevocably linkedto each other. Alesina and Roubin, (1996) have analyzed the relationship between political instability and economic growth. The results indicated the presence of inter-linkage between the two variables and reveal that the high probability of power change (i.e. political instability) leads to low growth rates.

Regional average GDP growth rate of South Asia has decreased from 5.93\% (2011) to 5.18\% (2015), whereas in case of Central \& East Asia, the same has decreased from $7.22 \%$ (2011) to $3.02 \%$ (2015), which is a remarkable drop. In the case of Southeast Asia, it has decreased from 6.59\% (2011) to 4.07\% (2015). Moreover, GDP per capita growth rates also exhibited a decreasing trend. Thus, it implies that economic growth is not sustainable in these regions ${ }^{5}$, which must be of concern of policy makers.

\footnotetext{
${ }^{2}$ Economic sustainability refers to the ability of an economy to consistently maintain respectable level of increasing gross domestic productivity (or maintenance of capital stock) over a long period of time (Daly, 1996).

${ }^{3}$ Social sustainability occurs when the formal and informal norms and processes are ensured; systems; structures; and relationships actively support the capacity of current and future generations to create healthy communities. Socially sustainable communities are equitable, diverse, connected $\&$ democratic and provide a good quality of life (Partridge, 2005).

${ }^{4}$ Environmental sustainability implies that environmental resources are utilized in a way that it becomes possible for civilizations to support themselves indefinitely (Daly, 1990).

${ }^{5}$ Regional averages are estimated by the authors using World Bank Open Data.
} 
Environmental sustainability has gained significant importance over time. It inculcates the scarcity of resources and minimizing environmental damages. It pertains to the choices which will affect all living beings, natural resources, and climate (Johnson et al., 1997). Therefore, environmental sustainability must be the focus of resource allocation. The research in this direction must consider biophysical limits, time dimension, social and value systems, as well as, uncertainty about changes in technology and human welfare. It is of the utmost importance to achieve because certain aspects of damage done to the natural ecosystem are irreversible (Hussen, 2000). Recent studies show that environmental protection, as well as, human capital may very well be the pre-requisites of sustaining economic growth in the long-run.

There are numerous factors which directly or indirectly affect the environmental sustainability of countries, including governance, income inequality, property rights, social inclusiveness, and women empowerment (Martinez, 2002). It is a general belief that the desire for environmental preservation occurs when the basic needs of the people are fulfilled. However, at that stage the natural resources may have already been damaged; therefore, it is important that developing countries also understand the necessity of environmental protection ${ }^{6}$. The whole world is victium of environmental degradation, which is posing health problem for many countries. Therefore, it is important to pay equal importance to it.

Various economic, social, and environmental issues persist in Asian economies. Poverty remains a pressing problem in South Asia with almost $40 \%$ of the region's population is living below poverty line (USD 1.25 a day). Additionally, $20 \%$ of the population lacks access to safe drinking water. It also has the lowest per capita energy consumption in the world. South Asia is facing many challenges in terms of balancing environmental sustainability and conserving resources (Rasul, 2014; 2016). Therefore, it is important to analyze how environmental sustainability may be achieved.

In Southeast Asia, destruction of coral reefs (about 95\% are at risk from coastal development, overfishing/destructive fishing, marine-based pollution,

\footnotetext{
${ }^{6}$ Developing countries have their major focus on increasing economic growth and they are less willing to allocate resources for pollution abatement; since their top most issue is ever increasing poverty. Whereas, developed countries spend more on environmental protection because fulfilling the basic needs of people is no longer a major concern in these countries. For example, annual expenditure on environmental protection in the USA is estimated to be, approximately, $2 \%$ of its GDP (Morgenstern et al. 1998). In spite of the above USA did not sign Keyoto Protocol.
} 
and/or watershed-based pollution) ${ }^{7}$, increasing deforestation and urbanization are among the major issues that are adversely affecting the environment. Average deforestation rate in the region is $7.78 \%$, while average urbanization rate is $3.63 \%$ $(2016)^{8}$. All these are creating threat to maintain environmental quality.

In the Central and East Asia, economic growth is achieved at the cost of environmental degradation. In China too, most of the greenhouse gases emissions is becoming an increasing threat. According to an estimate, air pollution in the region causes more than 50,000 premature deaths and 400,000 new cases of chronic bronchitis every year (World Bank, 2016).

The Asian economies are environmentally vulnerable with high values of the Environmental Vulnerability Index (EVI). Singapore has the highest value of EVI at 428 (country rank 233), whereas, Mongolia has the lowest value of EVI at 208 (country rank 8). It may be observed that Pakistan, India, Japan, and Philippines are also extremely vulnerable to environmental degradation ${ }^{9}$.

Given the above background, this study is focused on analyzing sustainable development in selected Asian economies. Sustainable development encompasses all three; economic sustainability, social sustainability, as well as, environmental sustainability. It requires that countries ameliorate institutional quality, administer natural resources, safeguard the environment, and attain social inclusiveness. It is the very reason that this study is focused to analyze, above cited three sustainable linkages i.e. economic, social and environmental sustainability. Moreover, this research also aims at analyzing synergy between environmental, social, and economic sustainability, as well as to provide pertinent policy implications in this regard.

The study consists of five sections. Section two provides literature review, section three methodology, while, the fourth section provides empirical results and its implications. Finally, conclusion and policy implications are provided in section five of the study.

\section{Literature Review}

This section of the study critically discusses the literature to divulge the importance of sustainable development in today's world. Inefficient institutional

\footnotetext{
${ }^{7}$ For more information, see Burke et. al. (2011).

${ }^{8}$ Regional averages are estimated by the author using World Bank Open Data.

${ }^{9}$ Environmental Vulnerability Index, Retrieved from; http://www.vulnerabilityindex.net/
} 
framework and disparities in economic opportunities across the globe have become an impeding influence on economic sustainability (Sneddon, Howarth, \& Norgaard, 2006). Declining stocks of critical natural assets and persistently negative genuine savings rates are clear indicators of un-sustainability (Pearce \& Atkinson, 1998).

Empirical literature on sustainable development that utilizes holistic approach is limited. Most of the studies focus on one or a few aspects of sustainability, while ignoring the rest. Lehtonen (2004) highlights the challenges of using a holistic approach to sustainable development, concluding that it is not feasible to devise a single framework to analyze every dimension of sustainable development. Moreover, there is a lack of consensus regarding the adequate measure of sustainable development (Parris \& Kates, 2003; Wilson et al., 2007). Moran, et al. (2008) measured sustainable development for ninety-three countries, considering only social and environmental dimensions. It is concluded that countries are moving away from sustainable development despite the efforts of policymakers to achieve it. However, economic sustainability is not accounted for in this analysis. Pierce, et al., (2016) focused only on social sustainability and argued that 'social capital' is an adequate indicator for measuring social sustainability.

Sustainable development holds two key implications; firstly, it proposes to prioritize needs of 'world's poor' and; secondly, it points out the limitations of environment's ability to meet the present and the future needs. Impartiality between and within generations is required to sustain human development, which is the essence of sustainable development (Anand \& Sen, 2000). Wealth maximization ${ }^{10}$ can be used to succor human development.

Cracolici, et. al. (2010) determines the relationship between economic and non-economic indicators of well-being, revealing that GDP is positively related to life expectancy, literacy rate, and the proxies of labor, capital stock, and technological progress. A positive relation between GDP and pollution is found, an increase in GDP increases $\mathrm{CO}_{2}$ emissions. Other important factors, such as institutional quality and income inequality are also significant in achieving economic sustainability (Brautigam \& Knack, 2004). Gradus and Smulders (1993) found that environmental care and long-run economic growth are inter-linked.

\footnotetext{
${ }^{10}$ Wealth maximization refers to the ability of a society to create and maintain its economic wealth over time (Anand and Sen, 2000).
} 
Sonnenfeld (2008) accentuates the importance of policies required to achieve social, economic, and environmental sustainability. Increasing globalization has brought about many environmental, institutional, and economic changes (Azhar, et al., 2007). Climate change is becoming one of the worst threats to sustainability (Guest, 2010). Therefore, new insights, policy changes, and implementation strategies are required, which will meet the needs of a changing world (Najam, et al., 2007). Intuitive understanding of sustainable development is of paramount importance to devise apposite policy measures.

The above-cited literature shows that although sustainable development has gained popularity in recent literature. Yet it has become difficult to correlate the diverse theoretical models, incorporating distinct measures and indicators, as used by different authors in their studies to claim their findings. Different combinations of these indices have been used by researchers, depending on the main objective of their analysis. There is hardly any comprehensive study which may have analyzed the multi-dimensional concept of sustainable development. There is a need to focus on economic, environmental, and social sustainability, which also incorporate factors having a direct or indirect impact on sustaining all the three aspects. In the past, data availability was a major problem in conducting such studies, especially in developing and transitional economies. Recently, some data has been compiled that covers a good range of indicators pertaining to the above-cited issues. Thus, this study attempts to bridge the gap in the literature in order to provide policy guidelines.

\section{Theoretical Background and Methodology}

At the core of sustainable development (SD), is the convergence of the economic, environmental, and social sustainability. The challenge is to perform an integrated analysis encompassing all the three aspects of sustainable development. Mostly, the researchers ignored their interdependence. There are few attempts at integrating social, economic, and environmental sustainability (Gibson, 2001, 2010), but such studies are focused on local concerns and decision-making process without considering global and institutional factors. This study attempts to achieve that end. The main objective is to pay adequate attention to the major factors which are crucial for sustainable development.

The purpose of this analysis is not to develop an indicator of sustainable development because numerous such indicators already exist ${ }^{11}$. As sustainable

\footnotetext{
${ }^{11}$ Such as Wellbeing Index, Ecological Footprint, Genuine Progress Indicator, Environmental Sustainability Index etc.
} 
development is not a goal to be achieved, rather it is an ongoing process to be maintained (Hjorth \& Bagheri, 2006), the methodology to study SD is developed with the following considerations ${ }^{12}$.

- Sustainable development is a dynamic process. Social, economic, and environmental sustainability are interlinked. Thus, the future trade-offs between these three pillars of sustainability must be considered while designing a sustainable development paradigm (Gibson, 2001, 2010).

- Environmental sustainability linkages include the risk of extreme events and the trade-offs between economic growth, social welfare, and the environment (Haimes, 1992).

- Equity, that implies fair resource allocation between competing interests, is at the core of sustainability (Robert, 1991; Mohai \& Bryant, 1992). Freedom, democracy, good governance, human well-being, empowerment, and social, as well as, economic inclusiveness is required to ensure inter-generational and intra-generational equity (Jabreen, 2008).

- In addition to this, any holistic approach to sustainable development needs to consider multiple decision makers. It implies that various international, national, regional, political and institutional concerns must be considered. Otherwise, policy implications may not achieve desirable goals. This issue brings into light the importance of awareness as well. Every country, region, and community need to be aware of the risks to the environment, society, and economy to safeguard sustainability.

\subsection{Modeling Sustainable Development}

The lack of an appropriate comprehensive econometric model for the empirical analysis of sustainable development (SD) may stem from the challenge of fully grasping the concept and defining it in an adequate manner ${ }^{13}$.

The world is constantly evolving and changing. Furthermore, human actions and policies have unintended consequences (Jacobs, 2010), thus coevolutionary and dynamic paradigm is required to analyze SD (Norton, 2005). SD should be modeled in an integrative system by simultaneously analyzing social, economic, and environmental sustainability in terms of their global interactions (Gibson, 2001; 2010). The model used in this study is a meta-system or a state of dynamic balance (Todorov \& Marinova, 2011), which is given in equation (1).

\footnotetext{
${ }^{12}$ For details, see (Haimes, 1992).

${ }^{13}$ There exist several definitions of sustainability (Parkin, 2000).
} 


\section{$\mathrm{SD}=\mathrm{NS} \oplus \mathrm{SS} \oplus \mathrm{ES}$}

Where, SD represents sustainable development and NS, SS, and ES are environmental sustainability, social sustainability, and economic sustainability, respectively. Equation (1) implies that NS, SS, and ES are interlinked. It is supposed that there are three sectors of the global world, i.e. the environment, society, and economy. Sustainable development is achieved only when all three pillars achieve sustainability, as depicted in equation (1).

\subsection{The Environment}

The natural resource have their limits (Daly, 1996; Hawken et al., 1999). Thus, environmental sustainability (NS) entails the efficient utilization of limited natural resources. It implies that environmental resources are utilized in a way that it becomes possible for civilizations to support themselves indefinitely. It is one of the three pillars of sustainable development. Natural capital should be allocated in a way that depletion of nonrenewable resources is accompanied by the development of a renewable substitute for that resource. Similarly, depletion rate of a renewable resource should not exceed the rate of regeneration. Furthermore, waste generation from human activities should not exceed the carrying capacity of the ecosystem (Daly, 1990).

Availability of natural capital stock $(\mathrm{Kn})$ is important for environmental sustainability ${ }^{14}$. Reduction in natural capital or environment degradation (ED) is the impact of human activity on the environment ${ }^{15}$, and it will have a negative impact on NS. Human impact on the environment can be reduced by adopting environment-friendly technology, better environmental resource management, and environmental protection. Thus, the technology change (TC) which makes use of resources more efficient, has a positive impact on NS because it reduces the effect of human activity on the environment (Chertow, 2000). Along the same lines, it can be postulated that globalization also affects NS because it increases human activity and natural resource depletion ${ }^{16}$. Policies are used to control the extent of human activity which leads to ED. Governance is an important factor, where institutional quality (IQ) is a transmission channel through which globalization effects environment. Good governance plays an effective role in countering the negative impacts of globalization on the environment (Anderson \& Blackhurst, 1992; Esty,

\footnotetext{
${ }^{14}$ Natural capital stock is among five types of capital stock which represent availability of resources necessary to achieve SD (Parkin et al., 2003).

${ }^{15}$ For more information see, Johnson et al., (1997).

${ }^{16}$ For details, also see (Speth, (2003); Wijen et al., (2005); Bruijn \& Opschoor, 1997).
} 
1994). Population growth rate (PG) and consumption per capita $(C)^{17}$ also influence the environment (Lutz et al., 2004). There could be a trade-off between social sustainability (SS) and economic sustainability (ES), and environmental sustainability (NS) ${ }^{18}$.

Risk of natural disasters in the world has increased substantially over the years, therefore, NS analysis needs to account for the future risk of natural disasters occurrences. Because of this reason environmental risk (ER) is introduced into the model. Based on above-cited relations and linkages, NS may be analyzed by estimating the following equation.

$N S_{i t}=\alpha+\beta_{1} E S_{i t}+\beta_{2} S S_{i t}+\beta_{3} K_{n_{i t}}+\beta_{4} E D_{i t}+\beta_{5} E R_{i t}+\beta_{6} T C_{i t}+\beta_{7} I Q_{i t}+$ $\beta_{8} P G_{i t}+\beta_{9} C_{i t}+\beta_{10} G_{i t}+\varepsilon_{1 i t}$

\subsection{The Society}

Environment sustainability (NS) and economic sustainability (ES) are the most widely analyzed aspects of sustainable development (SD), whereas, social sustainability (SS) is often assumed to accompany them. According to the Western Australian Council of Social Services, (Partridge, 2005); "Social sustainability occurs when the formal and informal processes; systems; structures; and relationships actively support the capacity of current and future generations to create healthy and livable communities. Socially sustainable communities are equitable, diverse, connected and democratic and provide a good quality of life."

Social sustainability can also be defined in terms of 'capabilities' as follows (Lehtonen, 2004); "guarantees for both present and future generations an improvement of the capabilities of well-being (social, economic, or environmental) for all, through the aspiration of equity on the one hand - as the intra-generational distribution of these capabilities - and their transmission across generations on the other hand." According to A. K. Sen (2000) ${ }^{19}$, social sustainability encompasses social equity, diversity, social cohesion, quality of life, human well-being,

\footnotetext{
17 Population and consumption per capita, along with technology contribute to environmental degradation. This relationship is often given by formula, I = PAT. It is a very simple way to describe environmental impact of human activities. (Chertow, 2000)

18 The recession of 2008 proved that social and economic sustainability (SS \& ES) have a direct relation with economic sustainability (ES). For more details see, http://www.thwink.org/sustain/glossary/Three Pillars of Sustainability.htm

19 Sen, A.K. (2000). The Ends and Means of Sustainability, keynote address at the International Conference on Transition to Sustainability, Tokyo, May.
} 
democracy, and maturity ${ }^{20}$. Speaking in terms of Sustainable Human Development it can be defined as; "development that promotes the capabilities of present people without compromising capabilities of future generations."

In this regard, natural resources and the environment constitutes the ways and means to enhance the standard of living, and ultimately improve human wellbeing $^{21}$. The indicating features of social sustainability include, equitable access to shelter, health, education, transportation, and recreational activities. It implies that the current generation does not limit the ability of future generations to have access to the same facilities and services. It ensures the freedom to participate in political procedures/democracy, as well as, awareness and ability to convey the importance of sustainability from one generation to the other. Moreover, the ability of the community to identify its needs and fulfilling them, along with the mechanism and institutional framework that allows political advocacy to meet the needs of the community where necessary ${ }^{22}$.

Social sustainability (SS) is often treated as an asset, which is present in societies at varying degrees and it could improve 'social capital.' It can also be considered as an objective to be achieved through careful policy considerations; focused on inclusive growth. Based on above discussion, it can be concluded that factors which effect SS include institutional quality (IQ), income inequality (YE), rate of urbanization (U), population density (PD), unemployment (Un), freedom $(\mathrm{F})$, democracy $(\mathrm{D})$, Pollution $(\mathrm{P})$, literacy rate $(\mathrm{L})$, economic growth (y), and inclusiveness (In). Therefore, an equation to identify the determinants of SS may be given as follows,

$S S_{i t}=\gamma+\delta_{1} y_{i t}+\delta_{2} I Q_{i t}+\delta_{3} Y E_{i t}+\delta_{4} U_{i t}+\delta_{5} P D_{i t}+\delta_{6} U_{n_{i t}}+\delta_{7} F_{i t}+\delta_{8} D_{i t}+$ $\delta_{9} L_{i t}+\delta_{10} P_{i t}+\delta_{11} I_{n_{i t}}+\varepsilon_{2 i t}$

\subsection{The Economy}

The economic sustainability (ES) refers to the ability of an economy to continue certain level of gross domestic productivity (or maintenance of capital stock) over a long period of time (Daly, 1996). In simple terms, economic growth refers to an increase in income level. The sustainable economic growth depends

\footnotetext{
${ }^{20}$ By "maturity" it means that the individuals accept the responsibility of consistent growth and improvement through broader social attributes.

${ }^{21}$ Anand, S. \& Sen, A.K. (1996). Sustainable Human Development: Concepts and Priorities, Office of Development Studies Discussion Paper, No. 1, UNDP, New York.

${ }^{22}$ For more details, see (Bramley, Dempsey, Power, \& Brown, 2006), (Omaan, \& Spangerberg, 2002) and (Hans-Boeckler-Foundation, 2001)
} 
upon the positive change in capital stock $(\mathrm{K})$. Factors which affect economic growth include investment level (I), foreign direct investment (FDI) ${ }^{23}$, and macroeconomic policy $(\mathrm{MP})^{24}$. Economic policy involves a level of uncertainty because the proposed policy may not yield expected results (Baker et al., 2016). Economic policy uncertainty (EPU) needs to be accounted for in a sustainability paradigm. Investment in R\&D and technology diffusion (DF) are also important factors which sustain economic growth. Technology diffusion increases total factor productivity (TFP). Developing countries spend very little on R\&D but may get benefit from the spillover effects from the developed countries (Savvides \& Zachariadis, 2005). Nevertheless, these are important drivers of economic growth to be considered for appropriate analysis.

Low and middle-income countries often rely on foreign assistance to accelerate and sustain economic growth. On one hand, foreign resources can help recipient countries to fill domestic resource gap, but on the other hand, it can lead to a debt trap, thus, translating into a slowdown of economic growth and development in a country (Gukurume, 2012). There are various studies that provide evidence of the positive effect of foreign aid on economic growth rates (Huang \& Quibria, 2015). Whereas, such studies are also available which provide evidence that aid is unproductive. It tends to result in larger bureaucracies and contributes to government inefficiencies (Friedman, 1995).

The previous discussion reveals that environmental and social sustainability may have a trade-off relationship with economic sustainability, thus, a modified model for ES can be stated as follows,

$E S_{i t}=\tau+\rho_{1} y_{i t-1}+\rho_{2} F D I_{i t}+\rho_{3} K_{i t}+\rho_{4} I_{i t}+\rho_{5} N S_{i t}+\rho_{6} M P_{i t} E P U_{i t}+\rho_{7} D F_{i t}+$ $\rho_{8} R \& D_{i t}+\rho_{9} F A_{i t}+\varepsilon_{3 i t}$

Equations (1), (2), (3), and (4) constitute sustainable development, environmental sustainability, social sustainability, and economic sustainability. It is a regional model to study SD using a holistic approach. The study uses panel data to estimate econometric model specified above. Due to data insufficiency the methodology of unbalanced panel analysis is employed ${ }^{25}$. All the variables are taken as indexes or percentages. Sustainable development model estimated in this

\footnotetext{
${ }^{23}$ For details, see (Borensztein, Gregorio, \& Lee, 1998).

${ }^{24}$ Fischer (1993) shows that good macroeconomic policy is necessary to sustain growth. Large budget deficits, inflation, and distorted foreign exchange markets are negatively related to economic growth.

${ }^{25}$ Unbalanced Panel analysis is more common in economics field. For further information on balanced and unbalanced cross sections, see Wooldridge $(2010 ; 2019)$.
} 
study is a dynamic simultaneous equations $\operatorname{model}^{26}$. In this model, equations are estimated simultaneously using the same dataset, therefore, there is a possibility that their error terms may be correlated. Hence, 3SLS is an appropriate technique to estimate the model. It allows for correlated errors between equations ${ }^{27}$. 3SLS is asymptotically efficient as compared to 2SLS (Schmidt, 1976). To test the reliability of the model Chi2 Statistic is taken into consideration ${ }^{28}$.

There are four models that are estimated in this study; pertaining to nineteen Asian economies and three geographic sub-groups ${ }^{29}$.

i. Asian economies from South Asia, Southeast Asia, and Central \& East Asia. ii. South Asian economies including Bangladesh, Bhutan, India, Nepal, Pakistan, and Sri Lanka.

iii. Southeast Asian economies including Cambodia, Indonesia, Malaysia, Philippines, Singapore, and Thailand.

iv. Central \& East Asian economies including China, Mongolia, Republic of Korea, Japan, Kazakhstan, Kyrgyzstan, and Tajikistan.

Sustainable development is a global issue which requires regional corporation; therefore, regional analysis is employed in this study. On one hand, Asian countries have high environmental vulnerabilities, on the other hand, these countries are most populated countries of Asia. Hence these economies are selected for analysis. In addition to this, it is generally assumed that panel data analysis is better than time series analysis because it increases the number of cases; and hence, the statistical power of the analysis. Furthermore, the dynamic model specification requires a large sample size. In case, the sample size is small or moderate, panel data may be used to salvage the accuracy and efficiency of dynamic regression equations (Kiviet, 1995).

\section{Empirical Results and their Economic Implications}

The empirical results are presented in table one. The interaction terms are introduced in the model to capture the effect of one predictor variable on a response variable; at different values of the other predictor variables. Theoretical background

\footnotetext{
${ }^{26}$ Dynamic panel models do not require stationarity of the data. However, mathematical transformations are employed to ensure all the variables are stationary. Also, see Mukherjee et. al. (2013).

${ }^{27}$ For more information, see Hayashi (2000).

${ }^{28} \mathrm{R}$-squared has no statistical meaning in case of 2SLS and 3SLS estimations.

${ }^{29}$ Note that not all countries in the selected regions are included for analysis, the reason behind it is unavailability of relevant data for the time-period under consideration. Hence, countries where data is available for all the variables for years 1996-2015 are included in the analysis.
} 
of the study proposed that the unique impact of explanatory variables on the dependent variable may not exist, rather explanatory variables have a combined effect. In this case, economic sustainability (ES), social sustainability (SS), and environmental sustainability (NS) are the predictor variables, whereas, sustainable development (SD) is the response variable. And the interaction terms ES*SS, ES*NS, and SS*NS measures the effects of interactions between economic, social, and environmental sustainability on sustainable development.

In Asia (see column three of Table 1), the interaction between social sustainability and economic sustainability (ES*SS) is negative. It must be noted that a negative interaction term does not imply a negative impact on SD, it only implies that with an increase in one variable, the joint impact of the two variables on SD is decreased ${ }^{30}$. A negative interaction term between variables means that the combined effect of these variables on sustainable development (SD) is less than their individual impacts. Furthermore, it is less than the sum of the individual effects of the variables. A significant interaction term suggests that both variables have a joint impact on $\mathrm{SD}^{31}$. The interaction between $\mathrm{SS}$ and environmental sustainability (NS) is also negative and statistically significant in Asia. It suggests that the effect of NS on SD differs depending on the level SS, and vice versa. However, interaction between economic and environmental sustainability is statistically insignificant.

Table 1: Sustainable Development Empirical Results

\begin{tabular}{llcccc}
\hline $\begin{array}{c}\text { Dependent } \\
\text { Variables }\end{array}$ & $\begin{array}{c}\text { Independent } \\
\text { Variables }\end{array}$ & Asia & $\begin{array}{c}\text { South } \\
\text { Asia }\end{array}$ & $\begin{array}{c}\text { Southeast } \\
\text { Asia }\end{array}$ & $\begin{array}{c}\text { Central \& } \\
\text { East Asia }\end{array}$ \\
\hline SD & & & & & \\
& NS & 0.087 & 0.2724 & 3.0093 & 0.3186 \\
& & $\left(0.459^{*}\right)$ & $(0.001)$ & $(0.000)$ & $(0.042)$ \\
& SS & 2.5072 & 8.83 & 0.3147 & 5.4953 \\
& ES & $(0.000)$ & $(0.000)$ & $(0.034)$ & $(0.000)$ \\
& \multirow{2}{*}{ ES*SS } & $(0.0843$ & -7.6900 & 4.1806 & 0.4142 \\
& & -1.0200 & $\left(0.514^{*}\right)$ & $(0.009)$ & $(0.001)$ \\
& & $(0.000)$ & $(0.000)$ & $(0.000)$ & $(0.094 *)$ \\
\hline
\end{tabular}

\footnotetext{
${ }^{30}$ For more detail on interpretation of interaction terms also see; Braumoeller (2004) and Bernhardt \& Jung (1979).

${ }^{31}$ The effect of ES on SD is $7.08+2.51-1.02 * S S$. For example, if SS is 1 then it is 8.57 i.e. an increase of one unit in ES increases SD by 8.57 units only when SS is 1. Thus, at different levels of Social sustainability the impact of Economic sustainability on the sustainable development will be of different magnitude. It is the combined effect of both SS and ES.
} 


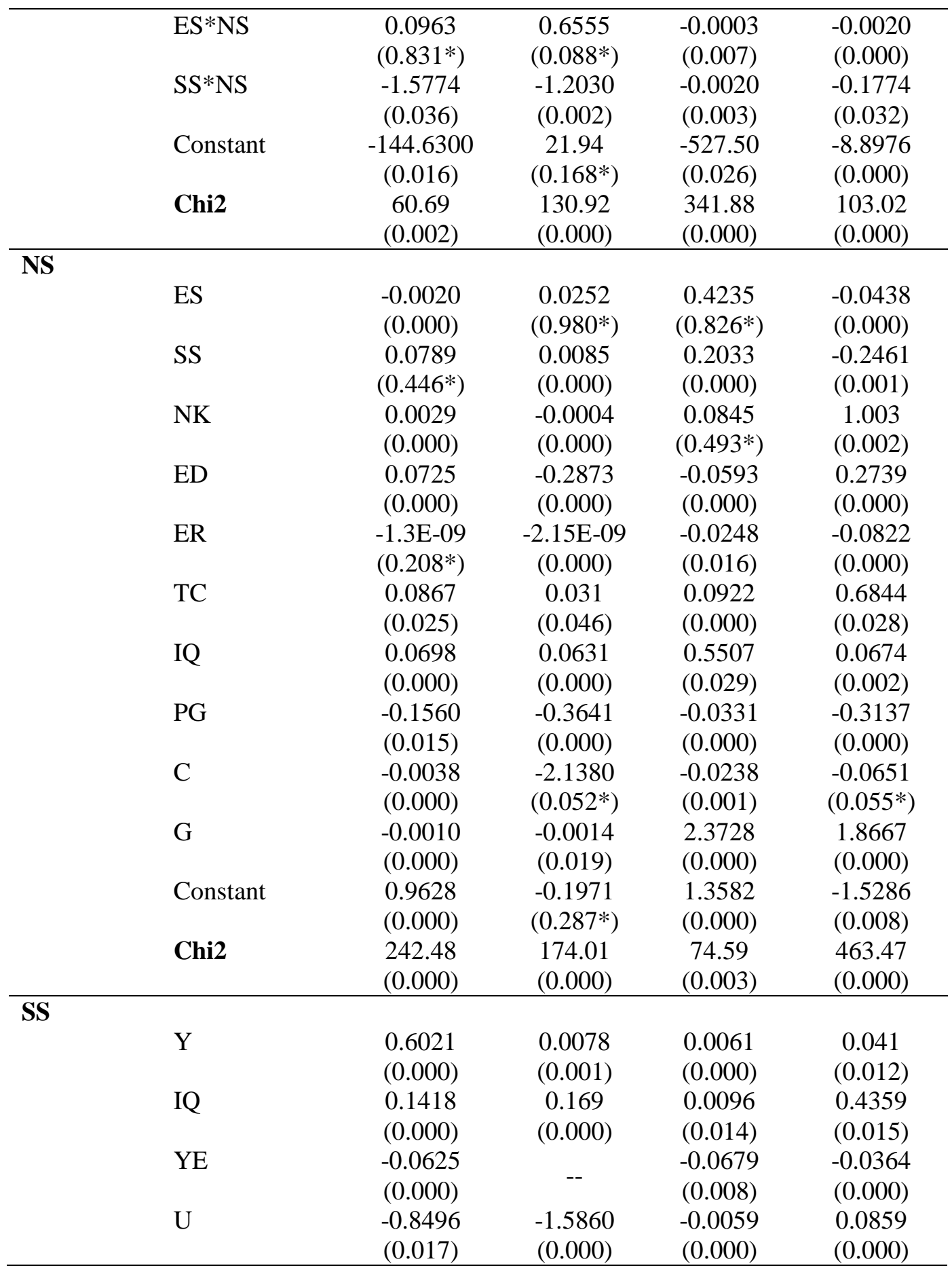


Sustainable Development: Economic, Social, and Environmental Sustainability in Asian Economies

\begin{tabular}{|c|c|c|c|c|c|}
\hline & $\mathrm{PD}$ & $\begin{array}{r}-0.0019 \\
(0.000)\end{array}$ & $\begin{array}{r}-0.0026 \\
(0.027)\end{array}$ & $\begin{array}{c}0.0039 \\
(0.127 *)\end{array}$ & $\begin{array}{r}-0.0049 \\
(0.000)\end{array}$ \\
\hline & Un & -0.1575 & -0.5530 & -0.0013 & -0.0493 \\
\hline & & $(0.000)$ & $(0.000)$ & $(0.002)$ & $(0.000)$ \\
\hline & $\mathrm{L}$ & 0.26 & & 0.0192 & \\
\hline & & $(0.000)$ & -- & $(0.112 *)$ & -- \\
\hline & CL & 0.0689 & 0.221 & 0.0005 & 0.0137 \\
\hline & & $(0.388 *)$ & $\left(0.584^{*}\right)$ & $(0.104 *)$ & $(0.000)$ \\
\hline & PR & 0.0083 & 0.203 & 0.1221 & 0.0351 \\
\hline & & $(0.861 *)$ & $(0.005)$ & $(0.036)$ & $(0.000)$ \\
\hline & ED & -0.9670 & -0.0628 & -0.0081 & -0.1336 \\
\hline & & $(0.005)$ & $(0.000)$ & $(0.437 *)$ & $(0.000)$ \\
\hline & GE & 0.0046 & 0.0113 & 0.0399 & 0.0377 \\
\hline & & $(0.000)$ & $(0.000)$ & $(0.000)$ & $(0.007)$ \\
\hline & ProR & 0.019 & 0.0245 & 0.0406 & 0.0127 \\
\hline & & $(0.000)$ & $(0.000)$ & $(0.011)$ & $(0.027)$ \\
\hline & Constant & 7.0454 & 9.978 & 3128.86 & 5434.12 \\
\hline & & $(0.000)$ & $(0.000)$ & $(0.000)$ & $(0.000)$ \\
\hline & Chi2 & 158.51 & 177.16 & 80.14 & 113.11 \\
\hline & & $(0.000)$ & $(0.000)$ & $(0.032)$ & $(0.000)$ \\
\hline ES & & & & & \\
\hline & $\mathrm{Y}(\mathrm{t}-1)$ & 0.0235 & 0.0721 & 0.1267 & 0.0756 \\
\hline & & $(0.005)$ & $(0.001)$ & $(0.000)$ & $(0.198 *)$ \\
\hline & $\mathrm{K}$ & 0.000245 & 0.015 & 0.0923 & 0.3018 \\
\hline & & $(0.003)$ & $(0.000)$ & $(0.005)$ & $(0.000)$ \\
\hline & I & 0.4327 & 0.489 & 0.3387 & 0.599 \\
\hline & & $(0.000)$ & $(0.000)$ & $(0.000)$ & $(0.000)$ \\
\hline & FDI & 0.0168 & 0.0553 & 0.0051 & -0.1089 \\
\hline & & $(0.218 *)$ & $\left(0.205^{*}\right)$ & $(0.096 *)$ & $(0.000)$ \\
\hline & DF & 0.2965 & 0.01 & & 0.1685 \\
\hline & & $(0.000)$ & $(0.000)$ & -- & $(0.004)$ \\
\hline & R\&D & 0.5782 & 0.1509 & 0.0053 & \\
\hline & & $(0.204 *)$ & $(0.000)$ & $(0.000)$ & -- \\
\hline & FA & 0.00183 & -0.0259 & 0.2325 & -0.0307 \\
\hline & & $(0.000)$ & $\left(0.536^{*}\right)$ & $(0.530 *)$ & $(0.102 *)$ \\
\hline & EPU & -0.0250 & -0.0148 & -0.1163 & -0.1528 \\
\hline & & $(0.038)$ & $(0.140 *)$ & $\left(0.280^{*}\right)$ & $\left(0.146^{*}\right)$ \\
\hline & $\mathrm{TC}$ & 0.6475 & 0.215 & 0.8031 & 0.2235 \\
\hline & & $(0.000)$ & $(0.599 *)$ & $(0.000)$ & $(0.002)$ \\
\hline & NS & -2.0631 & 0.029 & 0.1796 & 0.0648 \\
\hline & & $(0.003)$ & $(0.000)$ & $(0.015)$ & $(0.000)$ \\
\hline
\end{tabular}




\begin{tabular}{lcccc}
\hline SS & 1.113 & 0.1848 & 0.5971 & 1.2631 \\
& $(0.042)$ & $(0.000)$ & $(0.000)$ & $(0.000)$ \\
Chi2 & 157.89 & 174.39 & 278.72 & 340.36 \\
& $(0.000)$ & $(0.000)$ & $(0.000)$ & $(0.000)$ \\
\hline
\end{tabular}

Note: $\mathrm{P}$ values are provided in parentheses. Ignificant at confidence interval of $95 \%$, Variable is dropped because of insufficient data for the given region.

The situation of South Asian countries slightly differs from the aggregate results of Asia (see column four of table 1). Although, the interaction terms between economic sustainability and environmental sustainability (ES*NS) and between economic sustainability and social sustainability (ES*SS) are positive, interaction term between social sustainability and environmental sustainability (SS*NS) is negative. Moreover, ES*NS is statistically insignificant ${ }^{32}$. A positive interaction between variables implies that their combined effect on sustainable development (SD) is greater than their individual effects. Moreover, it is also greater than the sum of their individual effects. In Southeast Asia and Central \& East Asia (see columns five and six of table 1, respectively), the combined impact of environmental sustainability and economic sustainability (ES*NS), and that of environmental sustainability and social sustainability (SS*NS), as well as, the combined impact of economic sustainability and social sustainability (ES*SS) on the SD is less than their individual impacts, and less than the sum of their impacts on SD.

In Southeast Asia interaction terms between all three variables are statistically significant. In the case of Central \& East Asia, ES*SS is statistically insignificant, whilst coefficients of SS*NS and ES*NS are both statistically significant. Significant interaction terms between the variables imply that they have a combined impact on sustainable development (SD). Depending on the levels of social sustainability (SS), the impact of environmental sustainability (NS) on SD varies. Similarly, at different levels of economic sustainability (ES) the impact of NS on SD differs. It is true for the impacts of SS and ES as well. It reinforces the importance of achieving a balance between economic, social, and environmental objectives. Focusing on just one, while ignoring the other two, maybe a hindrance to the path of sustainable development. As observed, a possible reason for negative interaction terms may be lack of convergence between SS, ES, and NS in these regions of Asia.

\footnotetext{
${ }^{32}$ Interaction term ES*NS in South Asia is significant at $10 \%$ significance level, but study considered $5 \%$ level of significance.
} 
The variables which affect environmental, social, and economic sustainability are also analyzed in this study (see table 1). Results reveal that in the case of Asia and Central \& East Asia, economic sustainability (ES) has a statistically significant negative impact on environmental sustainability (NS). It may be rationalized by noting that ES entails an increase in economic growth, however, it leads to environmental degradation, thus decreasing environmental sustainability. It may be pointed out that Asian economies are at early stages of development and there is a need to keep a balance between economic and environmental objectives. A negative relationship may indicate the existence of a trade-off between economic sustainability and environmental sustainability. It should also be noted that this is the most populated region of the world. Unprecedented population growth rates have a negative impact on environmental sustainability. The per capita income in most of these countries is low and thus economic sustainability may not lead to environmental sustainability. Therefore, prioritizing ES while ignoring NS may not be advisable in Asian economies. In South Asia and Southeast Asia, ES does not have a statistically significant impact on NS.

The social sustainability (SS) has a positive effect on environmental sustainability (NS) in the cases of Asia, South Asia, and Southeast Asia, whereas, in Central and East Asia SS it has a negative impact on NS. Furthermore, in the case of Asia, it is statistically insignificant. The positive impact of SS on NS is expected because the increase in SS entails an increase in social cohesion, and social inclusiveness, therefore, it reduces the negative impact of human activities on the environment (Sen, 2000). The negative impact of social sustainability (SS) on environmental sustainability (NS) in the case of Central \& East Asian region, is unexpected. It may imply a trade-off between the two variables. Environmental risk (ER) and environmental sustainability (NS) are negatively related to each other in all regions. Thus, an increase in ER decreases NS. The result is as expected because high environmental risk puts a strain on both environmental resources usage, as well as, its capacity to absorb negative impacts of economic activities. Hence, to achieve sustainability the environmental risk needs to be minimized ${ }^{33}$.

An increase in natural capital (NK) increases environmental sustainability (NS) in Asia and Central \& East Asia. In South Asia, however, NK and NS have a negative relationship. The natural capital $(\mathrm{NK})$ is the environmental stock of

\footnotetext{
${ }^{33}$ For more details on environmental risk and its consequences, see Green Growth, Resources and Resilience; Environmental Sustainability in Asia and the Pacific, United Nations and Asian Development Bank Publication, 2012.
} 
resources ${ }^{34}$, therefore, the increase in NK implies that the usage of natural resources has increased, leading to an increase in production capacity. A positive relationship between NK and NS, thus, means that increasing exploitation of natural resources is beneficial for the country/region because an increase in NK leads to an increase in economic growth. Whereas, a negative relationship between NK and NS implies undue exploitation of natural resources in a way which is harmful to the environmental sustainability. From the results, it is inferred that increasing exploitation of natural resources is unsustainable only in the South Asian region. In Southeast Asia, the relationships between NK and NS is statistically insignificant.

Environmental degradation (ED) and environmental sustainability (NS) are positively related in the case of Asia and Central \& East Asia. However, in the case of South Asia and Southeast Asia, environmental degradation (ED) has a negative effect on environmental sustainability (NS). The negative effect of environmental degradation (ED) on environmental sustainability (NS) is as expected. With increase (or decrease) in ED, NS decreases (or increases). Whereas, a positive relationship between ED and NS is unexpected. The positive effect of ED on NS may be rationalized because increase (or decrease) in ED may be an indication of change in resource base in the region ${ }^{35}$. Moreover, it may be explained considering that NS is measured in terms of $\mathrm{CO} 2$ emissions per GDP (i.e. CO2/GDP), while $\mathrm{ED}$ is an index that includes various aspects of pollution including $\mathrm{CO} 2$ emissions. Therefore, if $\mathrm{CO} 2$ is increasing then both ED and NS will increase, unless GDP increases more than the increase in $\mathrm{CO} 2$ emissions. In case of a greater increase in GDP than $\mathrm{CO} 2$ emissions, NS will decrease with an increase in $\mathrm{CO} 2$. Thus, from a positive relationship between NS and $\mathrm{ED}$, it may be deduced that $\mathrm{CO} 2$ emission in Asia is increasing faster than the increase in GDP, which is damaging and could create an environmental threat to the region. The same is true in the case of Central $\&$ East Asian countries.

The technological change (TC) and institutional quality (IQ) both have a positive impact on environmental sustainability (NS) in all regions of Asia. It is as per expectations because better technology ensures environmental protection, so it does better institutional quality, hence both have a positive impact on NS.

\footnotetext{
34 Examples of natural capital include: minerals; water; waste assimilation; carbon dioxide absorption; arable land; habitat; fossil fuels; erosion control; recreation; visual amenity; biodiversity; temperature regulation and oxygen.

35 When more natural resources are exploited ED increases, however, accompanying increase in natural capital may counter the negative effect of ED on NS.
} 
The population growth rate (PG), consumption (C), and globalization $(\mathrm{G})$ have a negative relation with environmental sustainability (NS) in Asia. These results are as envisioned. Population growth puts pressure on natural resources and environmental degradation, thus, decreasing environmental sustainability (NS). Similarly, increase in (C) results in increased economic activity, which in turn decreases NS. Globalization (G), on the other hand, may have either a positive or a negative impact on NS because it depends on the externalities resulting from an increase in global integration. These externalities may be positive or negative; some of the positive environmental externalities resulting from globalization include the adoption of better technologies, resulting in an increase in environmental protection. And global cooperation to ensure environmental sustainability. Whereas, some of the negative externalities include an increase in pollution, and an increase in exploitation of natural resources, in an unsustainable way. In the case of Asia, an increase in G decreases NS demonstrating that increase in globalization is not conducive to the environment of the region, most probably due to the negative externalities that arise because of rapid globalization.

Population growth rate (PG) and consumption (C) have a negative impact on environmental sustainability (NS) of its sub-regions. Moreover, globalization (G) has a negative impact in the case of South Asia. Whereas, in the cases of Southeast Asia and Central \& East Asia, globalization (G) and environmental sustainability (NS) have a positive relationship. Therefore, there is an indication that in these two regions increase in the global integration is beneficial for the environment.

The economic growth (Y; i.e. annual GDP per capita growth rate) has a positive impact on the social sustainability (SS) in Asia, South Asia, Southeast Asia, as well as, Central and East Asia. Increase in GDP per capita growth rate manifests into better health, education, and shelter opportunities for people. The institutional quality (IQ) also has a positive impact on social sustainability (SS) in all the regions, whereas, income inequality (YE) has a negative impact on SS. Better institutional quality (IQ) ensures that fruits of increase in income are reaped by the people at large, thus no wonder it has a positive impact on SS. Whereas, high-income inequality reduces access to better health, education, employment, and other opportunities for people, therefore, decreasing social sustainability. For the same reason, the unemployment level (Un) has a negative impact on SS in Asia and its three sub-regions.

Furthermore, urbanization (U), population density (PD), and environmental degradation (ED) have a negative impact on social sustainability (SS) in Asia, and 
South Asia. In Southeast Asia, U and ED have a negative impact on SS, whereas, PD is positive and statistically insignificant in this case. While, in Central \& East Asia PD and ED have a negative relationship with SS, but U has a positive effect on SS. The increase in U and PD puts pressure not only on the environment but also on the societies, therefore, it decreases SS. The positive effect of U on SS in Central $\&$ East Asian countries suggests that urbanization is not putting pressure on the societies, in fact, it is beneficial for them. It must be noted that Asian economies are rapidly urbanizing economies ${ }^{36}$. Moreover, East Asia is leading in this regard, China's urban population has almost doubled in the last decade. In addition to this, the percentage of population living in 'urban slums' is less in East Asia (28\% of urban population) as compared to South Asia and Southeast Asia, therefore, urbanization in Central \& East Asia has a positive rather than negative impact on $\mathrm{SS}^{37}$. Environmental degradation also has many social consequences, such as health problems, thus it affects SS negatively in all selected regions.

The adult literacy rate (LR), political rights (PR), civil liberties index (CL), gender equality (GE), and freedom of property rights (ProR) show a positive relationship with social sustainability (SS) in all regions of Asia. However, CL is statistically significant only in Central \& East Asia. Whereas, PR is statistically insignificant in Asia and LR is insignificant in the South \& East Asia. An increase in LR increases awareness among people, as well as, social cohesion, therefore, its positive effect on the sustainability of the societies in as expected. It is true in case of the Southeast Asian region as well. The variables CL, PR, GE, and ProR represent social inclusion and has the potential to increase SS in Asian economies.

The lagged GDP growth rate (Yt-1), capital (K), investment (I), foreign direct investment (FDI), and foreign aid (FA), all show a positive relation with economic sustainability (ES) of Asian regions, except in Central \& East Asia where FDI, as well as, FA effect ES negatively and South Asia where the impact of FA on ES is negative. Indicating that relying on foreign aid may not be conducive for economic sustainability in these regions. Note that FDI is statistically insignificant in all regions except Central \& East Asia, while FA is significant only in the case

\footnotetext{
${ }^{36}$ According to United Nations urbanization rate in Asia could increase to $56 \%$ by 2030 and $64 \%$ to 2050 .

${ }^{37}$ It is observed that developed countries are highly urbanized economies, thus, increase in urbanization provides an opportunity for the countries to move towards prosperity and social welfare. However, managing urbanization is important. For instance, in South Asia, 35\% of urban population lives in slums, while in Southeast Asia it is $31 \%$. Thus, inadequate urban planning in these regions has resulted in lack of social services, increase in urban poverty, and insufficient urban infrastructure. (West, 2014).
} 
of Asia. These are all financial variables, which are important to sustain the economies, hence their positive impact on ES is as expected, and however, statistical insignificance may indicate discrepancies in the data ${ }^{38}$.

The technology diffusion (DF), investment in R\&D, and technology change (TC) also have a positive impact on ES, for all regions. The positive effect of DF, $\mathrm{R} \& \mathrm{D}$, and TC is expected because adoption of new and better technologies is the key to sustainable economic growth in the long-run. The economic policy uncertainty (EPU) affects economic sustainability (ES) negatively in all regions. Thus, an increase in global economic policy uncertainty decreases economic sustainability.

In Asia, social sustainability (SS) affects economic sustainability (ES) positively. Whereas, environmental sustainability (NS) has a negative impact on ES. Thus, where an increase in SS increases ES, there exists a trade-off between NS and ES. The trade-off between the economic prosperity and environmental protection is often highlighted in the economic literature, whereas, there is a consensus about the complementary nature of social and economic prosperities. Although, there is no comparative study that exists in literature, theoretically the trade-off between any of the three pillars of sustainable development (i.e. social, economic, and environmental) is a possibility.

\section{Conclusion and Policy Implications}

The purpose of this study is to analyze sustainable development and to explore the relationship, and interlink between social, economic, and environmental aspects of sustainable development in Asia and its three sub-regions. The increase in economic activity has resulted in an increase in environmental degradation. It is more important than ever to adopt policies which result in sustaining the society, economy, as well as, the environment. The survival of all living beings depends on following the integrated path of sustainable development.

To draw empirical evidences, an econometric model is utilized. The findings show that in Asia, there is a trade-off between environmental sustainability and economic sustainability implying that Asian countries should focus on a balance between economic and environmental sustainability while devising policies. When these countries focus solely on economic sustainability,

\footnotetext{
38 The term statistical insignificant is not the same as theoretical, or practical significance (Borror, 2009). Therefore, when an explanatory variable is statistically insignificant at a certain significance level, it means that null-hypothesis of corresponding coefficient being zero cannot be rejected, however, it does not mean that it is certainly 0. For more information also see, (Ryan, 2008).
} 
environmental sustainability cannot be achieved. It is revealed that, overall for Asia, increasing integration with the global economy is not beneficial to environmental sustainability. Technological change has a positive impact on the environmental, as well as, economic sustainability of the region. Therefore, focus on technological improvements needs to be strengthened. Social inclusiveness, freedom, and democracy affect social sustainability positively. Moreover, institutional quality has a positive relationship with social and environmental sustainability. Thus, further improvements in institutional quality are called for. Furthermore, environmental degradation also affects social sustainability negatively, which may hamper human health and reduces natural capital.

In addition, unemployment, rapid urbanization, growing income inequality, and population density have a negative impact on social sustainability in Asia and South Asian regions. It calls for improvements in these areas. However, in Southeast Asia, population density and in Central \& East Asia, urbanization has a positive effect on social sustainability. It may be noted that population density in South Asia is greater than two comparative regions. High population growth rate affects environmental sustainability negatively. These economies need policies that may help to eradicate the negative impacts of these variables. There is a need to protect the environment along with the increase in economic development.

The study is a rudimentary empirical investigation and further research in this regard could help further to improve policy interference. The study does not distinguish between short-term and long-term effects of the key variables on SD. An investigation of the lag structure of key variables in the SD process based on panel data would, therefore, be an extension of this work. Since direction of causality between economic, social, and environmental factors is not addressed in this study, therefore, further insights into the process of SD may help more to achieve such sustain abilities. 


\section{References}

Ahmed M. Hussen. (2000). Principles of environmental economics: economics, ecology and public policy. Routledge.

Alesina, A. O. S and Roubini, N. (1996). Political instability and economic growth. Journal of Economic Growth, 189-211.

Anand, S., \& Sen, A. (2000). Human development and economic sustainability. World development, 28(12), 2029-2049.

Anand, S., \& Sen, A. K. (1996). Sustainable human development: concepts and priorities.

Anderson, K., \& Blackhurst, R. (1992). The greening of world trade issues. Harvester Wheatsheaf.

Azhar, U., Khalil, S., \& Ahmed, M. H. (2007). Environmental effects of trade liberalisation: a case study of Pakistan. The Pakistan Development Review, 645-655.

Baker, S. R., Bloom, N., \& Davis, S. J. (2016). Measuring economic policy uncertainty. The quarterly journal of economics, 131(4), 1593-1636.

Barro, R. J. (1996). Institutions and growth, an introductory essay. Journal of Economic Growth, 145-148.

Beder, S. (1994). The role of technology in sustainable development. IEEE Technology and Society Magazine, 13(4), 14-19.

Bernhardt, I., \& Jung, B. S. (1979). The interpretation of least squares regression with interaction or polynomial terms. The Review of Economics and Statistics, 481-483.

Borensztein, E., De Gregorio, J., \& Lee, J. W. (1998). How does foreign Direct Investment affect economic growth? Journal of International Economics.

Borror, C. M. (Ed.). (2009). The certified quality engineer handbook. ASQ Quality Press.

Bramley, G., Dempsey, N., Power, S., \& Brown, C. (2006, April). What is 'social sustainability', and how do our existing urban forms perform in nurturing it. In Sustainable Communities and Green Futures' Conference, Bartlett School of Planning, University College London, London.

Braumoeller, B. F. (2004). Hypothesis testing and multiplicative interaction terms. International Organization, 58(4), 807-820. 
Bräutigam, D. A., \& Knack, S. (2004). Foreign aid, institutions, and governance in sub-Saharan Africa. Economic Development and Cultural Change, 52(2), 255-285.

Burke, L., Reytar, K., Spalding, M., \& Perry, A. (2011). Reefs at risk revisited. World Resources Institute.

Chertow, M. R. (2000). The IPAT equation and its variants. Journal of Industrial Ecology, 4(4), 13-29.

Cracolici, M. F., Cuffaro, M., \& Nijkamp, P. (2010). The measurement of economic, social and environmental performance of countries: A novel approach. Social Indicators Research, 95(2), 339.

Daly, H. E. (1990). Toward some operational principles of sustainable development. Ecological Economics, 2(1), 1-6.

Daly, H. E. (1996). Beyond growth: the economics of sustainable development. Beacon Press.

De Bruyn, S. M., \& Opschoor, J. B. (1997). Developments in the throughputincome relationship: theoretical and empirical observations. Ecological Economics, 20(3), 255-268.

Ding, Y. (2003). Impacts of Affluence and Overexploitation of Natural Resources. Environment and Development. Encyclopaedia of life support systems, 1 .

Esty, D. C. (1994). Greening the GATT: Trade, environment, and the future. Peterson Institute.

Fischer, S. (1993). The role of macroeconomic factors in growth. Journal of monetary economics, 32(3), 485-512.

Friedman, M. (1995). Foreign economic aid: Means and objectives (No. 60). Hoover Press.

Gibson, R. B. (2001). Specification of sustainability-based environmental assessment decision criteria and implications for determining" significance" in environmental assessment. Ottawa: Canadian Environmental Assessment Agency.

Gibson, R. B. (2010). Beyond the pillars: sustainability assessment as a framework for effective integration of social, economic and ecological considerations in significant decision-making. In Tools, Techniques and Approaches for 
Sustainability: collected writings in environmental assessment policy and management (pp. 389-410).

Gradus, R., \& Smulders, S. (1993). The trade-off between environmental care and long-term growth - pollution in three prototype growth models. Journal of Economics, 58(1), 25-51.

Guest, R. (2010). The economics of sustainability in the context of climate change: An overview. Journal of World Business, 45(4), 326-335.

Gukurume, S. (2012). Interrogating foreign aid and the sustainable development conundrum in African countries: A Zimbabwean experience of debt trap and service delivery. International Journal of Politics and Good Governance, 3(3.4), 1-20.

Haimes, Y. Y. (1992). Sustainable development: a holistic approach to natural resource management. IEEE Transactions on Systems, Man, and Cybernetics, 22(3), 413-417.

Hans-Böckler-Stiftung, E. (2001). Pathways towards a sustainable future. Düsseldorf, Hans Böckler Stiftung.

Hawken, L. Lovins (1999) Hawken, P., Lovins, A., \& Lovins, LH (1999). Natural capitalism: Creating the next industrial revolution.

Hayashi, C. (2000). Econometrics. Princeton University Press.

Hjorth, P., \& Bagheri, A. (2006). Navigating towards sustainable development: A system dynamics approach. Futures, 38(1), 74-92.

Huang, Y., \& Quibria, M. G. (2015, August). The global partnership for sustainable development. In Natural Resources Forum (Vol. 39, No. 3-4, pp. 157-174).

Jabareen, Y. (2008). A new conceptual framework for sustainable development. Environment, development and sustainability, 10(2), 179192.

Jacobs, J. (2010). The nature of economies. Vintage Canada.

Johnson, D. L., Ambrose, S. H., Bassett, T. J., Bowen, M. L., Crummey, D. E., Isaacson, J. S., ... \& Winter-Nelson, A. E. (1997). Meanings of environmental terms. Journal of environmental quality, 26(3), 581-589.

Kates, R. W., Parris, T. M., \& Leiserowitz, A. A. (2005). Science and policy for sustainable development. Environment, 47(3), 8-21. 
Ki-Moon, B. (2013). The millennium development goals report 2013. United Nations Pubns.

Kiviet, J. F. (1995). On bias, inconsistency, and efficiency of various estimators in dynamic panel data models. Journal of econometrics, 68(1), 53-78.

Lehtonen, M. (2004). The environmental-social interface of sustainable development: capabilities, social capital, institutions. Ecological economics, 49(2), 199-214.

Lutz, W., Sanderson, W. C., \& Scherbov, S. (Eds.). (2004). The end of world population growth in the 21st century: New challenges for human capital formation and sustainable development. Earthscan.

Maser, C. (1997). Sustainable community development: principles and concepts.

Michie, J. (2001). The impact of foreign direct investment on human capital enhancement in developing countries. Report for the Organization for Economic Co-operation and Development (OECD).

Mohai, P., \& Bryant, B. (1992). Environmental injustice: weighing race and class as factors in the distribution of environmental hazards. U. Colo. L. Rev., 63, 921.

Moran, D. D., Wackernagel, M., Kitzes, J. A., Goldfinger, S. H., \& Boutaud, A. (2008). Measuring sustainable development-Nation by nation. Ecological economics, 64(3), 470-474.

Morgenstern, R. D., Pizer, W. A., \& Shih, J. S. (2001). The cost of environmental protection. Review of Economics and Statistics, 83(4), 732-738.

Mukherjee, C., White, H., \& Wuyts, M. (2013). Econometrics and data analysis for developing countries. Routledge.

Najam, A., Runnalls, D., \& Halle, M. (2007). Environment and Globalization: Five Propositions, International Institute of Sustainable Development. Retrieved on December 4, 2013.

Norton, B. G. (2005). Sustainability: A philosophy of adaptive ecosystem management. University of Chicago Press.

Omann, I., \& Spangenberg, J. H. (2002). Assessing Social Sustainability, The Social Dimension of Sustainability in a Socio-Economic Scenario. 
Parkin, S. (2000, November). Sustainable development: the concept and the practical challenge. In Proceedings of the Institution of Civil EngineersCivil Engineering (Vol. 138, No. 6, pp. 3-8). Thomas Telford Ltd.

Parkin, S., Sommer, F., \& Uren, S. (2003, March). Sustainable development: understanding the concept and practical challenge. In Proceedings of the Institution of Civil Engineers-Engineering Sustainability (Vol. 156, No. 1, pp. 19-26). Thomas Telford Ltd.

Parris, T. M., \& Kates, R. W. (2003). Characterizing and measuring sustainable development. Annual Review of environment and resources, 28(1), 559586.

Partridge, E. (2005, September). Social sustainability': a useful theoretical framework. In Australasian political science association annual conference (pp. 28-30).

Pearce, D., \& Atkinson, G. (1998). The concept of sustainable development: An evaluation of its usefulness ten years after Brundtland. Revue Suisse $d$ Economie Politique et de Statistique, 134, 251-270.

Pierce, J. C., Lovrich, N. P., \& Budd, W. W. (2016). Social capital, institutional performance, and sustainability in Italy's regions: Still evidence of enduring historical effects? The Social Science Journal, 53(3), 271-281.

Rasul, G. (2014). Food, water, and energy security in South Asia: A nexus perspective from the Hindu Kush Himalayan region $\boldsymbol{z}^{2}$ Environmental Science \& Policy, 39, 35-48.

Rasul, G. (2016). Managing the food, water, and energy nexus for achieving the Sustainable Development Goals in South Asia. Environmental Development, 18, 14-25.

Robèrt, K. H. (1991). Educating a nation: The natural step. context, 28(10).

Ryan, T. P. (2008). Modern regression methods (Vol. 655). John Wiley \& Sons.

Savvides, A., \& Zachariadis, M. (2005). International technology diffusion and the growth of TFP in the manufacturing sector of developing economies. Review of development economics, 9(4), 482-501.

Schmidt, P. (1976). Econometrics. New York: Marcel Dekker.

Sen, S. (2000). Atomic environment of high-field strength $\mathrm{Nd}$ and $\mathrm{Al}$ cations as dopants and major components in silicate glasses: a Nd LIII-edge and $\mathrm{Al} \mathrm{K}$ - 
edge X-ray absorption spectroscopic study. Journal of non-crystalline solids, 261(1-3), 226-236.

Sneddon, C., Howarth, R. B., \& Norgaard, R. B. (2006). Sustainable development in a post-Brundtland world. Ecological economics, 57(2), 253-268.

Sonnenfeld, D. A. (2008). Globalisation and environmental governance: Is another world possible? Global Environmental Change, 18(3), 341.

Speth, J. G. (2003). Worlds apart: globalization and the environment. Island Press.

Todorov, V., \& Marinova, D. (2011). Modelling sustainability. Mathematics and computers in simulation, 81(7), 1397-1408.

West, J. (2014, March 26). Urbanization and Slums in Asia. Retrieved from Asian Century Institute: http://www.asiancenturyinstitute.com/development/224urbanization-and-slums-in-asia

Wilson, J., Tyedmers, P., \& Pelot, R. (2007). Contrasting and comparing sustainable development indicator metrics. Ecological indicators, 7(2), 299-314.

Wooldridge, J. M. (2010). Econometric analysis of cross section and panel data. MIT press.

Wooldridge, J. M. (2019). Correlated random effects models with unbalanced panels. Journal of Econometrics, 211(1), 137-150.

World Bank Group. (2016). World development report 2016: digital dividends. World Bank Publications. 